Walter Reed Army Institute of Research (WRAIR) and the not-for-profit Henry M. Jackson Foundation, which sponsors research into military related medical problems-presented the program's budget and progress.

This small but highly respected group has been in the forefront of HIV research despite its small budget: identifying genetic diversity in HIV strains worldwide, documenting dual infection with $\mathrm{B}$ and E clades, developing the first serotyping system, setting up a worldwide HIV surveillance network and establishing cohorts for HIV vaccine trials in Thailand and Uganda.

According to Sam Avrett, executive director of the AIDS Vaccine Advocacy Council (AVAC) in Washington D.C. the military program received a congressional 'plus-up,' or extra funding, from Congress that was not included in the president's budget of $\$ 15$ million for FY96, 97 and 98. This brought their total funds for both basic and clinical research in HIV and HIV vaccines to around $\$ 40$ million in 1998, according to AVAC's May 1999 report, Eight Years and Counting: What Will Speed Development of an AIDS Vaccine?

But in FY99, the plus-up disappeared. With an additional $10 \%$ cut in the budget to support the US military efforts in Kosovo, WRAIR was left with $\$ 17$ million for the program-a 50\% reduction in usable scientific funds. Birx's fears that there would be no Congressional plus-up in FYOO were allayed the day after the PACHA meeting, when Congress agreed to add $\$ 10$ million to the budget, making an estimated $\$ 25.5$ million available for the military program. But even with this money-a \$5 million decrease in usable funds over FY98-WRAIR's HIV program remains underfunded.

PACHA was additionally concerned that a presidential initiative to budget $\$ 100$ million for AIDS prevention, mainly in Sub-Saharan Africa, be passed by Congress. And the committee asked for more information about a planned series of meetings-the first one was held by Hillary Clinton in early September-between government officials, business and foundation leaders, and members of community organizations to enlist support for international AIDS programs and policies. PACHA members were invited to this meeting only at the last minute.

Myrna Watanabe, Washington D.C.

\title{
Cloning regulators accused of operating in a vacuum
}

The move to ban human cloning without consideration of the legal and ethical issues surrounding reproductive technologies has prompted observers in Tokyo to call for the creation of an independent national bioethics committee. They say that, unlike other industrialized nations, Japan lacks guidelines on reproductive medicine with which to legislate against cloning.

A law prohibiting cloning is expected to pass the Japanese parliament by year's end. It has been drafted in accordance with a report by a bioethics panel established two years ago by the Council for Science and Technology (CST) -an advisory body chaired by the Japanese prime minister.

Motoya Katsuki, a developmental biologist at the Institute of Medical Sciences, University of Tokyo, and a member of the CST's cloning and human embryo research committees, condones a cloning ban, but says "to forbid human cloning in the absence of any consensus on the general handling of human embryos is hasty and without rationale." He fears that some researchers could now exploit reproductive techniques, which have become a lucrative and expanding business in Japan.

But Hiroo Imura, a permanent member of council and former dean of Kyoto

University, who chairs the CST's bioethics committee, defends the council's decision, arguing that it would have been unrealistic to aim for more comprehensive legislation: "Our goal was to deal with the issue of human cloning first." According to Imura, deliberations at the committee-the first proper bioethics advisory body in Japan-were protracted. Critics also counter that the CST's bioethics committee has yet to draft an agenda for its activities, a void seen by many as proof of the council's continued dependence on the Science and Technology Agency (STA).

Crunch-time for the committee should come with government reform in 2001, when the CST will have to operate independently of the STA. This will determine whether a bioethics committee with more extensive responsibilities than the present one, is required.

Robert TRIENDL, TOKyo

\section{NCI strikes unique agreement with Ireland}

Several senior members of the National Institutes of Health (NIH) descended on Belfast, Ireland last month, providing a show of solidarity for the NCI-All Ireland Cancer Agreement. The deal focuses on three areas: the enhancement and coordination of tumor registries in Ireland; improved informatics to support clinical trials throughout Ireland, and scholar exchange. The effort brings the Republic of Ireland and Northern Ireland together to fight the disease.

A conference held to mark the five-year agreement featured presentations by $\mathrm{NIH}$ Director Harold Varmus, National Cancer Institute (NCI) Director Richard Klausner, David Baltimore, Steve Rosenberg, Carmen Allegra, and the Chief Medical Officers of Northern Ireland and the Republic of Ireland.

Edison Liu, director of the NCI Division of Clinical Sciences, who was instrumental in organizing the conference, explained to Nature Medicine why
Ireland is the obvious choice for American backing in the field of oncology and cancer research. According to Liu, recent re-structuring efforts as a result of studies in the early 1990's that highlighted the higher cancer mortality

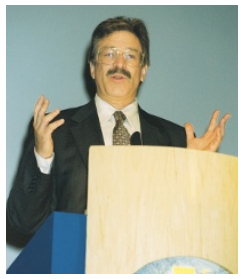

Richard Klausner in the UK and Ireland compared with the rest of Europe, now mean that Ireland has superior clinical cancer care within Europe.

"In addition, the Irish oncologic community comprises many specialists that have trained in the US and know the mind-set and practice format. Thus, there are personal links," says Liu. One such link exists with Patrick Johnston, head of oncology at Belfast City Hospital, who organized the conference with Liu. Johnston worked at NCI for nine years, "because the training was better than I could receive in Europe."

Liu also points to the relative political and economic stability of Ireland at the present time; the harmonization of gov- 